\title{
Dependence of polyethylene terephthalate crack-tip temperature on stress intensity and notch sensitivity
}

\author{
Bernard Chukwuemeka Ogazi-Onyemaechi, Yew Wei Leong and Hiroyuki Hamada \\ Polyethylene terephthalate (PET) is often thought to be extremely notch sensitive, as other amorphous or slow-crystallizing \\ polymers. However, our previous studies demonstrated three distinct fracture modes during tensile loading of PET when \\ notch depth was gradually increased, namely ductile, semiductile and brittle. Therefore, the notch sensitivity of PET is thought \\ to depend on its morphology and notch depth, whereas linear elastic fracture mechanics would be inadequate to characterize \\ the fracture toughness of PET, especially when the material is injection molded and possesses the characteristic skin-core \\ structure. This study revealed that the temperature at the crack tip significantly increased because of local plastic deformation \\ when the crack tip was situated within the skin region. As such, full ligament yielding was obtained, which allowed \\ characterization of the fracture toughness of PET using the principles of essential work of fracture (EWF). However, no \\ significant temperature increase occurred when specimens fractured in a brittle manner as the notch penetrated through \\ the skin and into the core. At this point, the material is said to be notch sensitive and is no longer able to undergo any \\ plastic deformation before failure. \\ Polymer Journal (2010) 42, 592-599; doi:10.1038/pj.2010.40; published online 26 May 2010
}

Keywords: crack-tip temperature; essential work of fracture; full ligament yielding; notch sensitivity; RPET; skin-core structure; VPET

\section{INTRODUCTION}

Fracture is a dissipative process during which plastic work is converted partly into heat, or heat is released during the fracture process itself. When the process is adiabatic, the released heat causes a local increase in temperature. ${ }^{1}$ When an adiabatic shear band is formed, there is a substantial increase in local temperature in the band. ${ }^{1}$ Therefore, heat dissipation due to the combined effect of plastic deformation (plastic flow) and fracture during tensile loading of polyethylene terephthalate (PET) is believed to affect the temperature around the stress concentration point, including the crack tip. This could also affect the magnitude of stress intensity on the stress field of the materials. The presence of voids, cracks, cavities or even impurities can influence stress and temperature distribution on tensile loading. The introduction of cracks in injection-molded flat bars affects their lines of stress. ${ }^{2,3}$ In an uncracked uniform bar (dumbbell), the stress concentration point is located at the center, and runs parallel to the direction of the applied force.

In injection-molded semicrystalline thermoplastics such as PET, the presence of skin and core layers is another factor that influences fracture behavior. ${ }^{4}$ It is known that some materials are more sensitive to cracks than are others. Therefore, it was suggested that stress-strain tests should be conducted on both notched and unnotched test specimens for comparison. ${ }^{5}$ Stress-strain tests enable design engineers to predict the fracture behavior of perfectly smooth (uniform) objects, but they do not allow prediction of the fracture behavior of objects with cuts. ${ }^{5}$ Deeply notched specimens, however, do not allow sufficient consideration of the contributions from the skin region toward the fracture behavior of the bulk.

Our previous study revealed three distinct fracture behaviors during tensile testing-ductile, semi-ductile and brittle-when notches ranging from 0.5 to $2.0 \mathrm{~mm}$ in depth were introduced to one side of a specimen of $10.0 \mathrm{~mm}$ in width. This variation in fracture behavior seems to be related to the skin-core structure of PET injection moldings. Semiductile failure was imminent when the notch depth fell within the thickness of the skin region. ${ }^{2}$ Therefore, it would be premature to assume that PET injection moldings are notch sensitive, especially when a deep notch is introduced that penetrates through the skin into the core region. This study evaluated the fracture toughness of PET injection moldings when notch depths were within the thickness of the skin region. The principles of essential work of fracture (EWF) were applied to elucidate the fracture toughness of moldings. EWF requires full ligament yielding to occur before crack displacement. Therefore, specimen temperatures were monitored during tensile tests to confirm localized ligament yielding to satisfy the requirements of EWF, as well as to pinpoint the regions in which the highest plastic flow occurred. Shallow notches of various depths were carefully machined into the injection moldings and their influence on the toughness and notch sensitivity of the PET bulk was elucidated. 


\section{MATERIALS AND METHODS}

\section{Material and sample preparation}

Amorphous grade neat PET (VPET) pellets (MA2103 LOT 601K; viscosity average molecular weight $=41499 \mathrm{~g} \mathrm{~mol}^{-1}$ ) were obtained from Unitika Co. Ltd. (Tokyo, Japan), and recycled PET (RPET) flakes (viscosity average molecular weight $=23131 \mathrm{~g} \mathrm{~mol}^{-1}$ ) were obtained from Yasuda-Sangyo Co. Ltd. (Kyoto, Japan). VPET pellets were used as received, whereas RPET flakes were extruded and pelletized before injection molding. Flakes were dried at $120^{\circ} \mathrm{C}$ for at least $5 \mathrm{~h}$ before extrusion by a single screw extruder (SR-Ruder Bambi SRV-P70/62; Nihon Yuki Co. Ltd., Osaka, Japan). Barrel temperature was set between 255 and $290{ }^{\circ} \mathrm{C}$ and the screw rotation speed was 50 r.p.m.

Before injection molding, VPET and RPET pellets were dried for at least $4 \mathrm{~h}$ at $130^{\circ} \mathrm{C}$ in a PICCOLO hopper-dryer from Itswa Co. Ltd. (Kyoto, Japan). Dumbbell samples $(10 \times 3 \mathrm{~mm})$ were fabricated with a Toyo PSS TI-30F6 injection-molding machine at a barrel temperature range of $250-270{ }^{\circ} \mathrm{C}$ (Toyo PSS Co. Ltd., Tokyo, Japan). Mold temperature was set at $30^{\circ} \mathrm{C}$, whereas injection and holding pressures were set at $60 \mathrm{kgf}$.

\section{Birefringence observation of skin-core morphology of injection- molded PET}

Birefringence was observed for a cross-section of dumbbell samples to gauge the sizes of the skin and core regions. Before polarized optical microscopy, a short section of dumbbell specimen was cut and placed in epoxy. One side of the cross-section was polished with a rotational polishing wheel mounted with abrasives of different grain sizes to achieve a smooth surface. The polished side was then mounted on a clean slide glass with epoxy glue to prevent moisture from penetrating between the glass and the sample surface during the polishing of the opposite end of the specimen. The second polishing step involved grinding the specimen down to a thickness of approximately $30 \mu \mathrm{m}$, which resulted in a smooth cross-section that was almost transparent. Polarized optical micrographs were taken from the polished specimen through a 3.34 megapixel Nikon digital camera attached to a $\times 10 / 0.25 \mathrm{P}$ magnification optical lens, which was mounted on a Nikon ECLIPSE E600 Polarizer (Nikon Co. Ltd., Tokyo, Japan). The micrographs were joined together using Adobe Photoshop CS software from Adobe Systems Inc. (San Jose, CA, USA). The resulting composite image ${ }^{2}$ was converted to gray mode (Figures 1 and 2) with Origin 7J [Rel v7.0265 (B265)] software from the OriginLab Corp. (Northampton, MA, USA); plots of the frequency and amplitude of the gray values were generated for the entire cross-section $(10 \times 3 \mathrm{~mm})$.

\section{Measurement of crystallinity in PET}

A JEOL TM-0015 microtome, JEOL was used to cut dumbbell specimens into 56 slices in the width direction (JEOL Co. Ltd., Tokyo, Japan). Each slice measured $50 \mu \mathrm{m}$ in thickness. The slices were taken in sequence corresponding

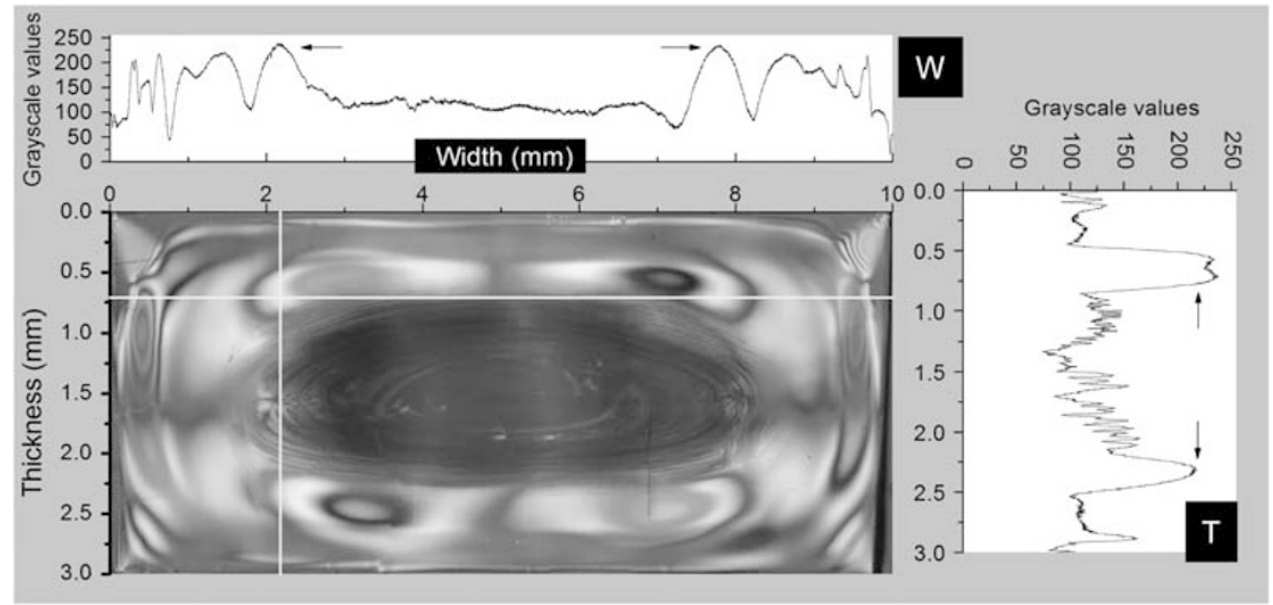

Figure 1 Gray image plots showing the gray values of the skin, interface and core regions of VPET (W is a plot of the gray values in the width direction, and $\mathrm{T}$ is a plot of the gray values in the thickness direction).

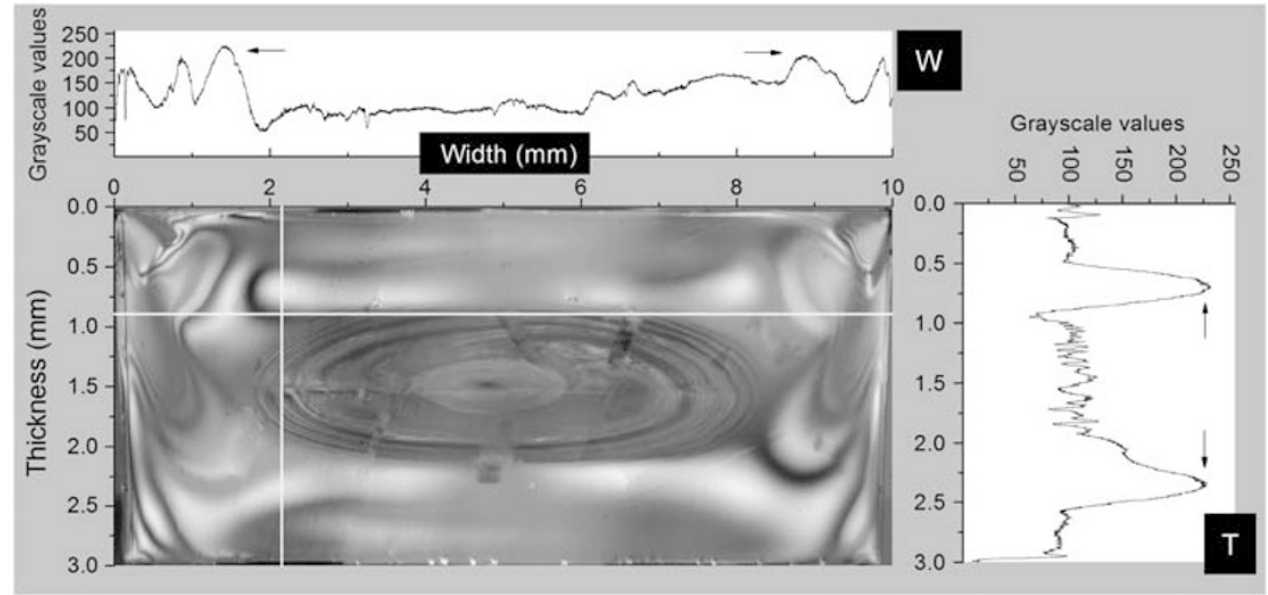

Figure 2 Gray image plots showing the gray values of the skin, interface and core regions of RPET (W is a plot of the gray values in the width direction, and $\mathrm{T}$ is a plot of the gray values in the thickness direction). 
Table 1 The crystallinity of VPET and RPET injection moldings

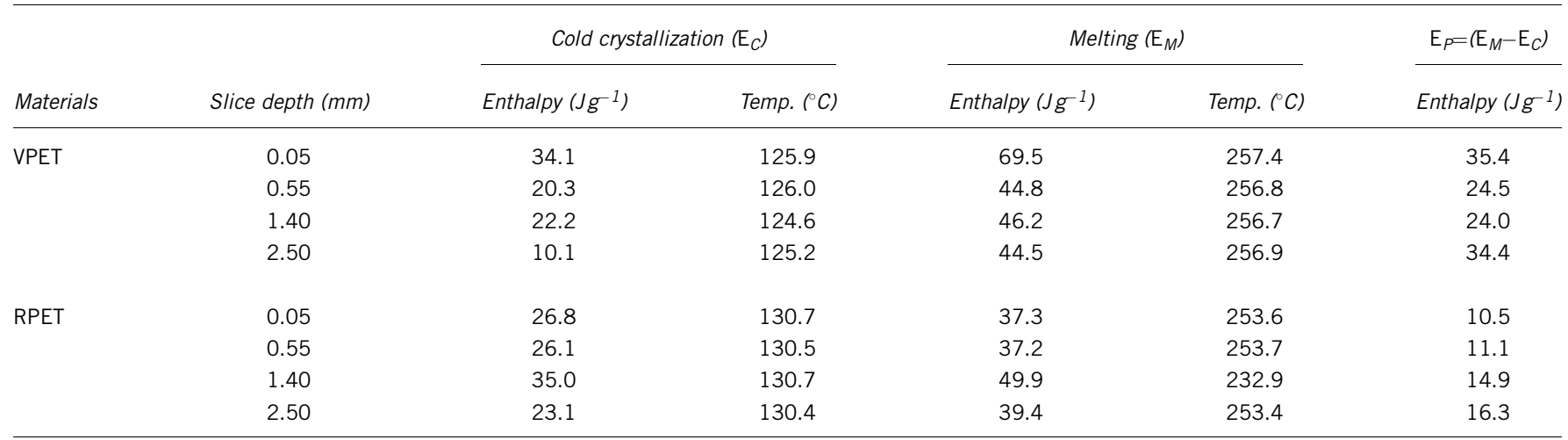

Abbreviations: RPET, recycled polyethylene terephthalate; Temp., temperature; VPET, amorphous grade neat polyethylene terephthalate.

to the skin, interface and mid-core regions of the specimens. Samples for differential scanning calorimetry were cut from the following slice depths: 50, 550, 1400 and $2500 \mu \mathrm{m}$ (as indicated in Table 1). Differential scanning calorimetry was conducted with a TA Instrument model 2920 modulated differential scanning analyzer from TA Instrument (Tokyo, Japan). The samples were heated from 30 to $300^{\circ} \mathrm{C}$ at $10^{\circ} \mathrm{C} \mathrm{min}^{-1}$. The melting enthalpies $\left(E_{\mathrm{M}}\right)$ of all specimens normalized with their respective enthalpies of cold crystallization $\left(E_{\mathrm{C}}\right)$ and melting $\left(E_{\mathrm{M}}\right)$ were measured from the resulting differential scanning calorimetry curves. The enthalpy of the materials due to processing $\left(E_{\mathrm{P}}\right)$ was then calculated by $\left(E_{\mathrm{P}}=E_{\mathrm{M}}-E_{\mathrm{C}}\right)$, as shown in Table 1 .

\section{Notching and mechanical property characterization}

V-notches of $0.5-3 \mathrm{~mm}$ depth were introduced into the width direction of dumbbell test pieces $(10 \times 3 \mathrm{~mm})$ with a Tool A-3 Digital Notching Machine (Toyo Seiki Manufacturing Co. Ltd., Tokyo, Japan). Notching was performed in stages of $0.5 \mathrm{~mm}$ depth to minimize internal sample deformation. The angle of the V-notches was in accordance with ASTM D256.

Tensile testing of notched and unnotched dumbbell specimens was performed with an Instron 4466 universal testing machine from Instron Japan Co. Ltd. (Osaka, Japan) mounted with a $10 \mathrm{kN}$ load cell and set at a cross-head speed of $10 \mathrm{~mm} \mathrm{~min}^{-1}$. At least seven sample pieces were tested for each material and notching condition.

\section{Monitoring of temperature distribution in specimens during the tensile test}

During the tensile test, an infrared video camera (TVS-200EX; NEC Avio Infrared Technologies Co. Ltd., Tokyo, Japan) was used to monitor the temperature distribution on the entire body of the test piece, including the crack tip. The camera speed was set at five frames per second, wherein each frame contained temperature readings taken from the start of the tensile test through the crack initiation and propagation stages. The infrared camera was set at an emissivity coefficient of 1.0 to approximate the 0.95 value for polymer materials (plastic opacity). Tensile tests were conducted at room temperature $\left(28^{\circ} \mathrm{C}\right)$. An infrared image analyzing software (Thermography Studio version 4.8; Nippon Avionics Co. Ltd., Tokyo, Japan) was used to export the temperature distributions and graph plots for analysis. The tensile test and infrared camera were started simultaneously; therefore, the temperature distribution in the specimens could be correlated to the stress-strain curves, as indicated in Figure 3.

\section{Notch sensitivity and temperature distribution}

Investigations were conducted on the effects of V-notches on the fracture behaviors of VPET and RPET by analyzing the notch sensitivity factors for yield strength $\left(k_{\mathrm{S}}\right)$ at different notch depths. This gives an understanding of the effects of notches on the fracture behavior of materials. If notches have no detrimental effects on yield strength and total energy absorbed on fracture, the notch sensitivity factors for yield strength $\left(k_{\mathrm{S}}\right)$ are equal to 1.0. Conversely,

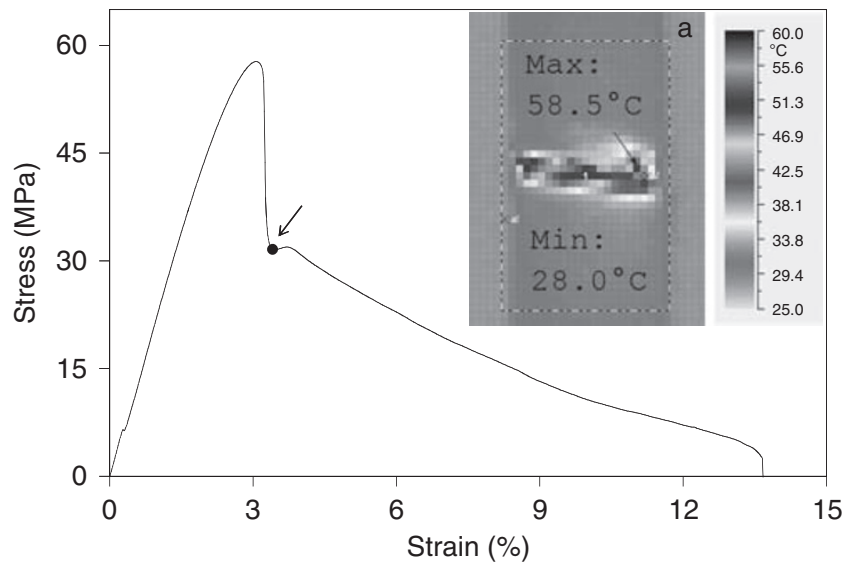

Figure 3 Determination of the maximum change in temperature (MCT) at full ligament yielding (indicated by arrow) of the stress-strain curves for different notch depths. Inset (a) shows the corresponding infrared image indicating the maximum and minimum temperatures. A full-color version of this figure is available at the Polymer Journal online.

if they have detrimental effects, the notch sensitivity factors are greater than $1.0{ }^{2,6}$ In this study, notch sensitivity factors are determined by the following equations:

$$
\kappa_{\mathrm{S}}=\left[\frac{\left(\mathrm{YS}_{0}\right) \times\left[t\left(w-a_{i}\right)\right]}{\left(\mathrm{YS}_{i}\right) \times(t w)}\right],
$$

where $k_{\mathrm{S}}$ is a notch sensitivity factor for yield strength, $\mathrm{YS}_{0}$ and $\mathrm{YS}_{i}$ represent the yield stress (strength) of unnotched and notched samples, respectively ( $i$ indicates different notch depths), $t$ is thickness, $w$ is width and $a$ is notch depth. ${ }^{2,6}$

The notch sensitivity factor for yield strength gives an understanding of how notches affect the strength of materials. ${ }^{2}$

The temperature distributions at the crack tips were correlated with the notch sensitivity factors. The maximum change in temperature (MCT) for each of the notch conditions was taken at full ligament yielding and determined by Equation (2) for notch depths with full ligament yielding. ${ }^{7}$ Conversely, the MCT for samples with brittle failures was taken at fracture. Corresponding infrared images, which show the yielding modes of the specimens, were extracted from the infrared video recordings taken during tensile tests, as indicated by the arrow in Figure 3, and from temperature readings in the inset (a).

$$
\mathrm{MCT}=T_{\max }-T_{\min },
$$

where $T_{\max }$ and $T_{\min }$ represent the maximum and minimum temperatures at full ligament yielding, respectively. 


\section{Determination of EWF}

The EWF is used to characterize highly ductile materials that exhibit full ligament yielding even on notching. The total works of fracture $\left(W_{\mathrm{f}}\right)$ in ductile materials under uniaxial tensile stress occur in two distinct deformation zones represented in the following equation: ${ }^{7-9}$

$$
W_{\mathrm{f}}=W_{\mathrm{e}}+W_{\mathrm{p}} .
$$

The EWF $\left(W_{\mathrm{e}}\right)$ is the work carried out in the process deformation zone, and the nonessential work of fracture $\left(W_{\mathrm{p}}\right)$ is the work carried out in the plastic deformation zone for actual crack opening and propagation. The EWF method requires that materials considered for analysis have full ligament yielding. ${ }^{7,10}$ EWF also requires a strong correlation $\left(R^{2}\right)$ between total specific work of fracture $\left(W_{\mathrm{f}}\right)$ and length of ligament. Hence, the following equation applies: ${ }^{7-9}$

$$
w_{\mathrm{f}}=\frac{W_{\mathrm{f}}}{l t}=w_{\mathrm{e}}+\beta w_{\mathrm{p}} l
$$

where $w_{\mathrm{f}}$ is the specific work of fracture, $l$ is ligament length, $t$ is sample thickness, $w_{\mathrm{e}}$ is the specific EWF or the failure work per unit surface area and $w_{\mathrm{p}}$ is the specific nonessential work of fracture or the plastic work per unit volume of the plastic deformation zone. $\beta$ represents the shape factor of the plastic deformation zone.

Equation (4) indicates that $w_{\mathrm{f}}$ is a linear function of $l$; therefore, $w_{\mathrm{e}}$ is the positive intercept at $l=0$ of the linear regression line of the data, and $\beta w_{\mathrm{p}}$ is the slope of the regression line. It is important to note that one of the objectives of EWF is to show that $w_{\mathrm{e}}$ is a toughness parameter. ${ }^{11}$

\section{RESULTS AND DISCUSSION}

\section{Cross-sectional observation by polarized light microscopy}

The plots obtained from the grayscale images of the cross-section of the samples revealed a complex morphology in which the existence of an interface between the skin and the core is clearly visible in VPET and RPET. Deviations from the intensity of the gray areas were used to precisely determine the thickness of the skin and core regions, as shown in Figures 1 and 2. The plots marked with $W$ and $T$ represent the intensity values of the grayscale in the width and thickness directions of the samples, respectively. The horizontal and vertical cursors on the matrix (grayscale image) were adjusted along the width and thickness directions until well-defined frequency peaks were obtained. The center region between the two maximum peak intensities (marked with arrows) obtained from the $W$ and $T$ plots were taken to be the core width and core thickness, respectively. The remaining areas surrounding the core will be regarded as the skin. As notches were introduced in the width direction, the size of the skin region in this direction is noted to be about $1.5 \mathrm{~mm}$ on each side of the specimen. Subsequent discussion will reveal the role of the skin region in the plastic flow of materials during plastic deformation (fracture), and its effects on fracture behavior and change in crack-tip temperature.

\section{Measurement of crystallinity in PET}

The skin region of the dumbbell samples was measured to be about $1.5 \mathrm{~mm}$, as shown in Figures 1 and 2. The effect of crystallinity was investigated at different notch depths, with particular focus on the $1.5 \mathrm{~mm}$ skin region. Table 1 clearly shows that $E_{\mathrm{p}}$ is high at the $0.05 \mathrm{~mm}$ layer of the skin. However, $E_{\mathrm{p}}$ decreased with increasing slice depth, but increased rapidly when the slice depth penetrated through the interface $(1.4 \mathrm{~mm})$ to the core $(2.5 \mathrm{~mm})$ layers, signifying different levels of crystallinity at different layers of the skin core. This seems to be consistent with the skin-core structure, as indicated by arrows on the enclosing peaks in Figures 1 and 2. The $E_{\mathrm{P}}$ of VPET is higher than that of RPET.

\section{The effect of notches and fracture modes on the change in temperature and the shape of plastic deformation zones}

Figure 3 shows the determination of the change in temperature at full ligament yielding, as indicated by the arrow. The inset shows an example of a corresponding infrared thermography (IT) image. Figures $4 \mathrm{a}-\mathrm{f}$ and $5 \mathrm{a}-\mathrm{f}$ show IT images at full ligament yielding of the specimens with different notch depths for VPET and RPET, respectively. The IT images of specimens with brittle fracture are shown in Figures $4 \mathrm{~g}-\mathrm{i}$ and $5 \mathrm{~g}-\mathrm{i}$. The IT images and temperature readings shown in Figures $4 \mathrm{a}$ and $5 \mathrm{a}$ of unnotched specimens show
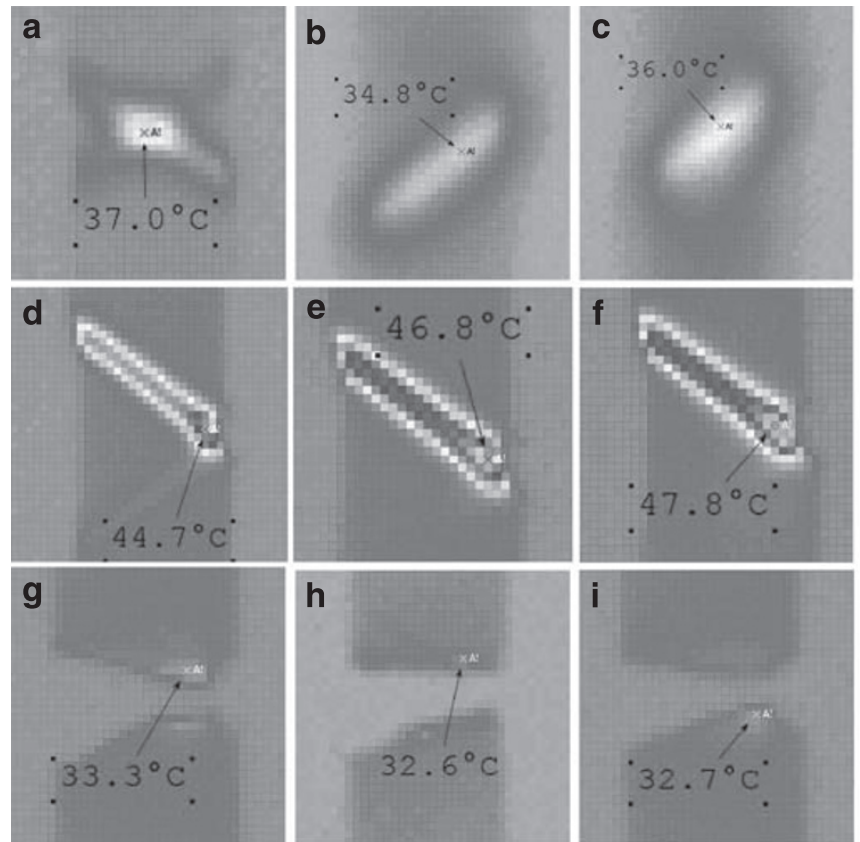

Temperature Scale

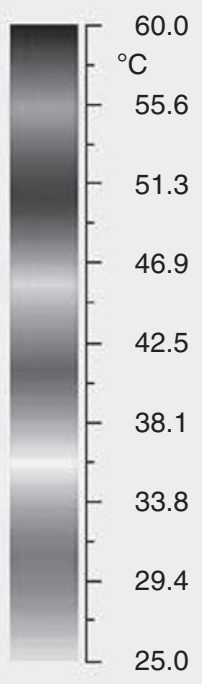

Figure 4 Infrared images of VPET showing fracture modes at different notch depths in which temperature changes were maximal at the foot of the neck (a) unnotched samples; (b) and (c) $0.5-0.9 \mathrm{~mm}$ notch depth; (d) $1.0 \mathrm{~mm}$; (e) $1.3 \mathrm{~mm}$; (f) $1.5 \mathrm{~mm}$; and (g-i) $1.7 \mathrm{~mm}$ and above). A full-color version of this figure is available at the Polymer Journal online. 


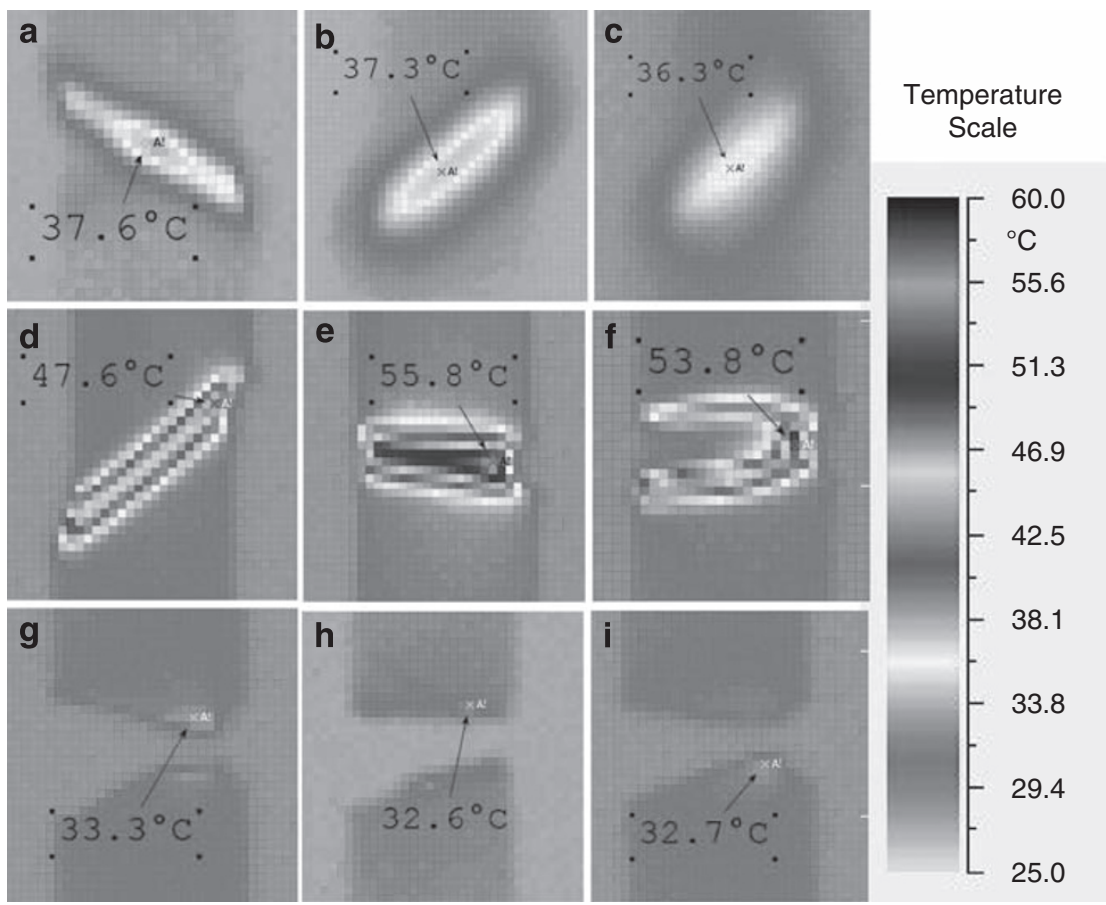

Figure 5 Infrared images of RPET showing fracture modes at different notch depths in which temperature changes were maximal at the foot of the neck (a) unnotched samples; (b, c) $0.5-0.9 \mathrm{~mm}$ notch depth; (d) $1.0 \mathrm{~mm}$; (e) $1.3 \mathrm{~mm}$; (f) $1.5 \mathrm{~mm}$; and (g-i) $1.7 \mathrm{~mm}$ and above). A full-color version of this figure is available at the Polymer Journal online.

that stress is concentrated at the center of the material where the maximum temperature is recorded, suggesting that the lines of stress are parallel to the direction of applied stress. ${ }^{3}$ However, when 0.5-0.9 mm-deep notches were introduced, the stress concentration point gradually shifted toward the crack tip as shown in Figures $4 b, c$ and $5 b, c$, suggesting that these notches, which were still located at the skin region, were able to yield and plastically deform at the notch root. The IT images (Figures $4 \mathrm{~b}$ and $\mathrm{c}$ ) show similar shapes in the plastic deformation zones, suggesting similar fracture behavior at these notch depths. The introduction of $1.0-1.5 \mathrm{~mm}$-deep notches resulted in a remarkable change in the shape of the deformation zone, and showed that the crack tip became an effective stress concentrator, giving rise to a phenomenal increase in the change in temperature as shown in the IT images (Figures $4 \mathrm{~d}-\mathrm{f}$ ). Figures $4 \mathrm{a}-\mathrm{f}$ and $5 \mathrm{a}-\mathrm{f}$ show that the specimens had full ligament yielding. The introduction of notches deeper than $1.5 \mathrm{~mm}$ resulted in brittle failure without yielding and therefore no change in temperature was observed as shown in IT images (Figures $4 \mathrm{~g}-\mathrm{i}$ ).

\section{Distribution of temperature at the crack tip during plastic deformation}

The three plastic deformation shapes discussed above are further explained with their temperature distributions in Figures $6 a$ and b, which were recorded during tensile testing, and correspond to different notch depths within the skin-core region. The figure shows four distinct temperature distributions at three different notch ranges as indicated by plots $a, b, c$ and $d$. Plots $a$ in Figure 6 show that VPET and RPET had similar temperature distributions when specimens were unnotched. However, temperature changes are higher in RPET than in VPET. The difference in temperature between VPET and RPET could be explained both by the elbow shape formed at full ligament yielding indicated by arrows on plots $a$ and by the shape of the plastic deformation zone previously shown in Figures $4 \mathrm{a}$ and 5a. Similar temperature distributions for the materials occurred at semiductile failure (0.5-0.9 mm-deep notches), as indicated by plots $b$ in Figure 6 . The resulting change in temperature is equally higher in RPET as in VPET with increasing prominence of the elbow shape on plots $b$ as indicated by the arrow. The second regime of temperature changes occurred at 1.0-1.5 mm-deep notches (represented by plots $c$ ), which indicate the terminal end of the skin region. Plots $c$ show that deepening notches created sharper points at full ligament yielding as indicated by the arrows. This could be consistent with the shapes of the plastic deformation zones in Figures $4 \mathrm{~d}$, e and 5d, e. RPET consistently has a higher change in temperature and a sharper yield point at full ligament yielding. This could be the effect of the lower modulus of resilience in RPET, which could have been because of lower crystallinity (Table 1). Finally, the third temperature phase was in brittle fracture at $1.7-3.0 \mathrm{~mm}$-deep notches (depicted by plots $d$ ).

It is important to observe the different degrees of sharp points indicated by arrows at full ligament yielding for the different notch ranges. The mild points in Figure 6, plots $a$, indicate that unnotched samples have a uniform geometry and stress is uniformly distributed and concentrated at the center of the materials, as shown earlier in Figures $4 \mathrm{a}$ and $5 \mathrm{a}$. This would have dissipated energy more evenly over the entire bulk of the material, resulting in only a small change in temperature. Similar to unnotched samples, the introduction of notches of $0.5-0.9 \mathrm{~mm}$ did not create significant sharp points or changes in temperature as shown by arrows on plots $b$ in Figure 6, indicating that this is the semiductile phase. The reason for this lack of change is that these notches were still within the skin region and did not become effective stress concentration points at the start of the tensile test. ${ }^{2}$ Notches must reach deep enough and close enough to the core region $(1.0-1.5 \mathrm{~mm})$ to become an effective stress concentration point right from the start of tensile stress. Therefore, at the point of shear and necking, mixed-mode fracture preceded by crazing occurred (refer to Figure 10b in Ogazi-Onyemaechi et al. ${ }^{2}$ ). This resulted in a remarkable change in temperature, particularly in RPET, as indicated 
by a very sharp point shown by the arrow in plots $c$ Figure 6 . On the basis of its location, the notch (within the terminal end of the skin and interface) could have activated a higher molecular chain movement and strain-induced crystallinity that resulted in a higher intensity
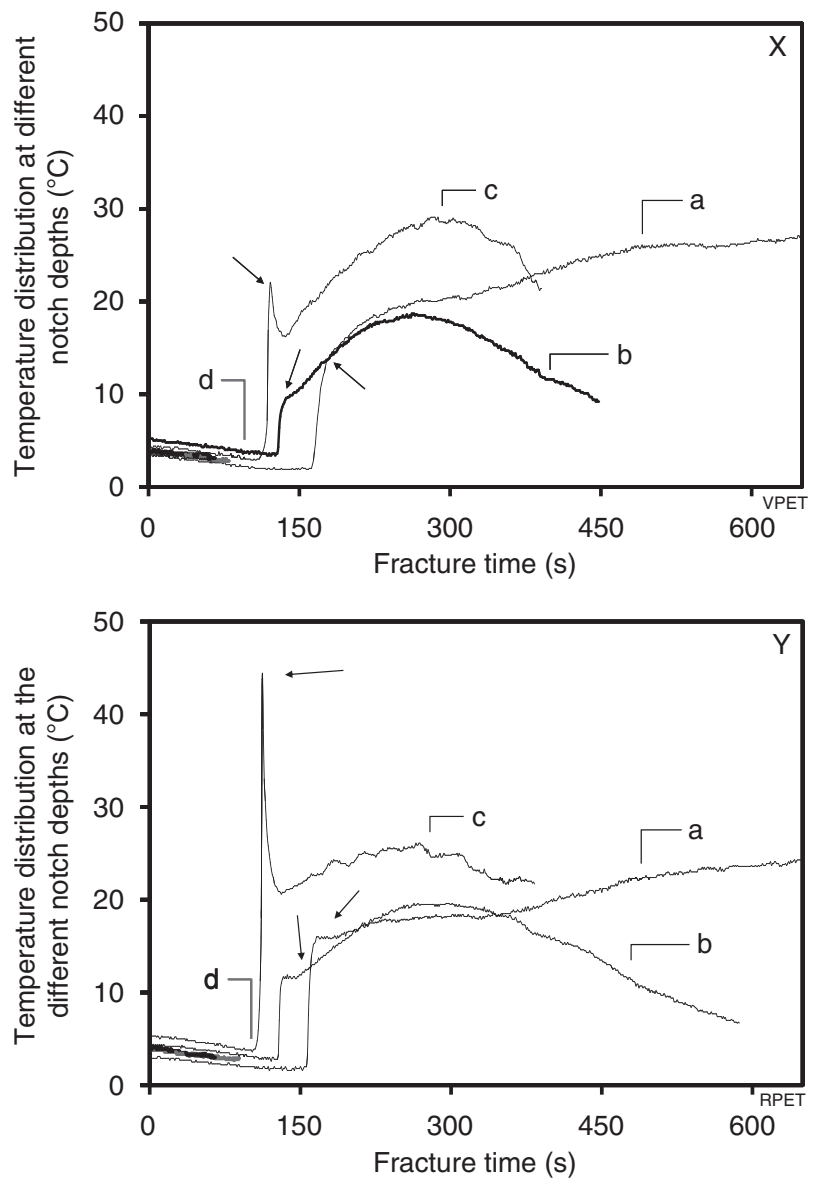

Figure 6 Crack-tip temperature distributions of VPET (X) and RPET (Y) samples showing the degrees of change at the skin, interface and core regions ( $a$ : unnotched samples; $b: 0.5-0.9 \mathrm{~mm}$ notch depth; c: $1.0-1.5 \mathrm{~mm}$; and $\mathrm{d}: 1.7-3.0 \mathrm{~mm}$; arrows indicate the temperature at full ligament yielding).

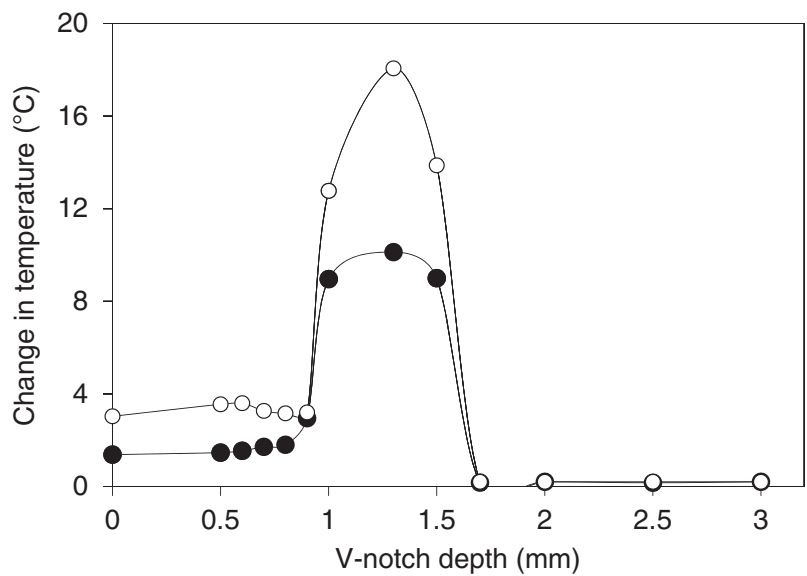

Figure 7 Maximum change in crack-tip temperature in the process zone showing a drastic increase at the interface $(1.0-1.5 \mathrm{~mm}$ notch depth) between the skin and core regions. of mixed-mode fracture preceded by a high degree of crazing (refer to Figure 10b in Ogazi-Onyemaechi et al. ${ }^{2}$ ), which is a major mechanism for temperature change. ${ }^{11}$ Notches deeper than $1.5 \mathrm{~mm}$ resulted in brittle failure, with zero $\left(0.2^{\circ} \mathrm{C}\right)$ change in temperature as shown in Figure 6, plots $d$.

Figure 7 clearly shows that the change in temperature is higher in RPET than in VPET. The figure shows that when materials had no notches, RPET had a higher change in temperature $\left(3.0^{\circ} \mathrm{C}\right)$ than VPET $\left(1.4^{\circ} \mathrm{C}\right)$. At the introduction of $0.5 \mathrm{~mm}$-deep notches, the change in temperature increased to 3.5 and $1.5^{\circ} \mathrm{C}$ in RPET and VPET, respectively. Similar temperature increases were observed when notches deeper than $0.5 \mathrm{~mm}$ but less than $1.0 \mathrm{~mm}$ were introduced in RPET and VPET specimens. Remarkable temperature increases were observed when $1.0-1.5 \mathrm{~mm}$-deep notches were introduced. However, the introduction of notches deeper than $1.5 \mathrm{~mm}$ resulted in brittle fracture without any change in temperature. RPET consistently has a greater change in temperature at all notch depths than does VPET. These observations are consistent with the earlier discussion of Figure 6. The above results show that the changes in crack-tip temperature were largely influenced by the length of the ligament or notch depth and by the plastic flow from the skin region to the crack tip.

Correlation between notch sensitivity factors for strength $\left(k_{\mathrm{S}}\right)$ and change in temperature at the crack tip

Figure 8 shows the correlation between notch sensitivity factor for strength $\left(k_{\mathrm{S}}\right)$ and change in temperature. This figure shows that when the crack tip was situated within the skin region, that is, less than $1.0 \mathrm{~mm}$ deep, $k_{\mathrm{S}}$ gradually decreased whereas the change in temperature remained less than $5^{\circ} \mathrm{C}$. When the notch penetrated the interface between the skin and the core $(1.0-1.5 \mathrm{~mm})$, it became an effective stress concentration point, resulting in a remarkable increase in cracktip temperature (more than $8^{\circ} \mathrm{C}$ ) at full ligament yielding. The introduction of notches deeper than $1.5 \mathrm{~mm}$ resulted in brittle fracture without a noticeable change in temperature (less than $0.2^{\circ} \mathrm{C}$ ). Figure 8 shows that VPET underwent a sudden transition in fracture behavior when a $1.0 \mathrm{~mm}$-deep notch was introduced, suggesting a tendency toward brittle fracture. This reveals that the notch sensitivity, change in temperature and fracture behavior of VPET are consistent with its distinct skin-core structure. Conversely, RPET exhibits a more gradual change in temperature, suggesting a gradual transition in fracture

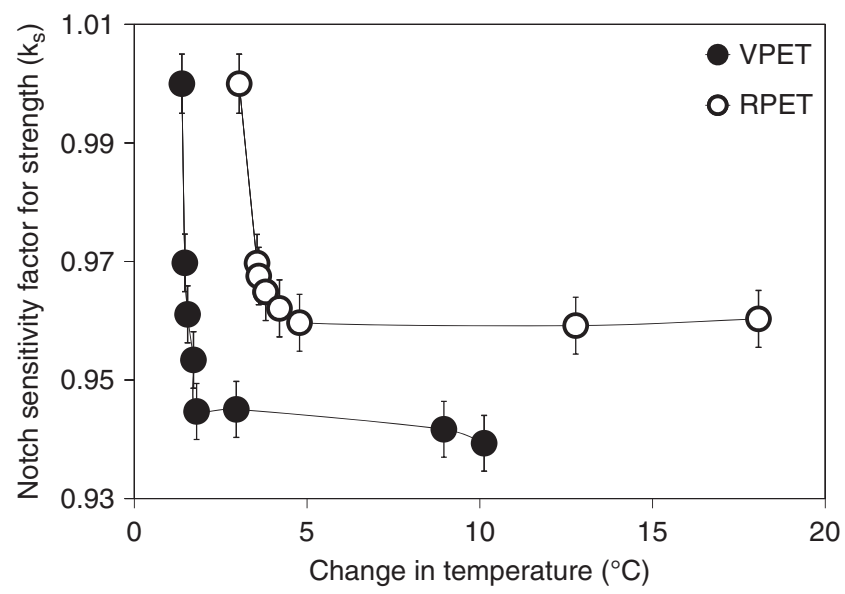

Figure 8 Correlation between the notch sensitivity factor for strength and crack-tip temperature at different notch depths. 

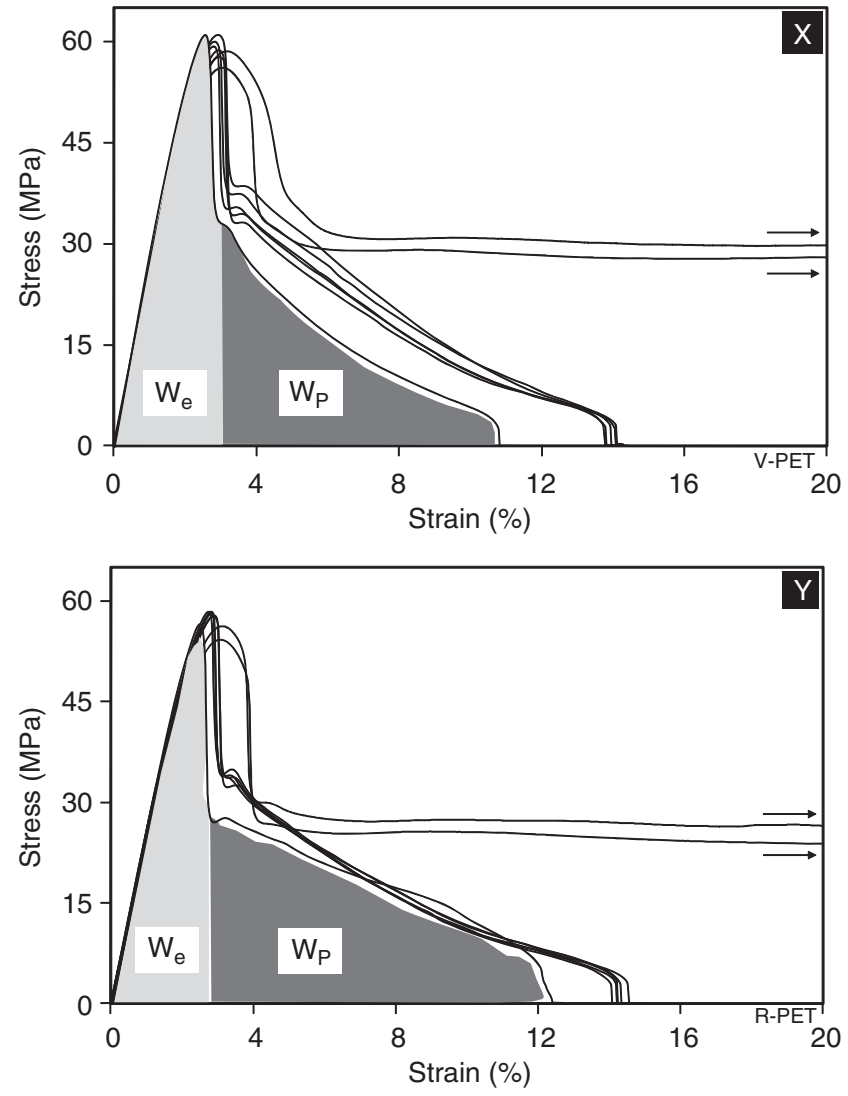

Figure 9 Stress-strain curves showing the essential $\left(W_{\mathrm{e}}\right)$ and nonessential $\left(W_{p}\right)$ works of fracture deformation zones for specimens at different notches ranging from unnotched (Un) to $1.5 \mathrm{~mm}$ (X: VPET; Y: RPET).

behavior that also reveals that the notch sensitivity, change in temperature and fracture behavior of RPET depend on its more dispersed and diffused skin-core structure. The results in Figure 8 are consistent with the observation in the preceding discussion, and they reveal that the notch depth or length of ligament and plastic flow from the skin region influenced the change in temperature.

Fracture behavior of single edge notched PET specimens and characterization by EWF

Our results have shown that unnotched PET is a highly ductile material and that notches would reduce the work performed during the fracture process, as depicted in the typical stress-strain curves in Figure 9. The VPET and RPET samples with $\leqslant 0.5 \mathrm{~mm}$-deep notches maintained high ductility and did not fracture below 300\% strain. However, the introduction of a $0.6 \mathrm{~mm}$-deep notch resulted in a drastic reduction in the ductility of both materials, with a consequent reduction in the total work performed during fracture. Figure 9 indicates that full ligament yielding occurred in samples when notches $\leqslant 1.5 \mathrm{~mm}$ deep were introduced, which satisfies an important requirement for performing the EWF analysis. ${ }^{11}$ The two distinct deformation zones are indicated as the process zone (essential zone, $W_{\mathrm{e}}$ ) and the plastic zone (nonessential zone, $W_{\mathrm{p}}$ ), which combine to form the total work of fracture $\left(W_{\mathrm{f}}\right)$.

The plots in Figure 10 show a strong linear relationship between the total work of fracture $\left(W_{\mathrm{f}}\right)$ and the length of the specimens' ligaments $(l)$. Therefore, the specific works of fracture $\left(w_{\mathrm{f}}\right)$ can be obtained by

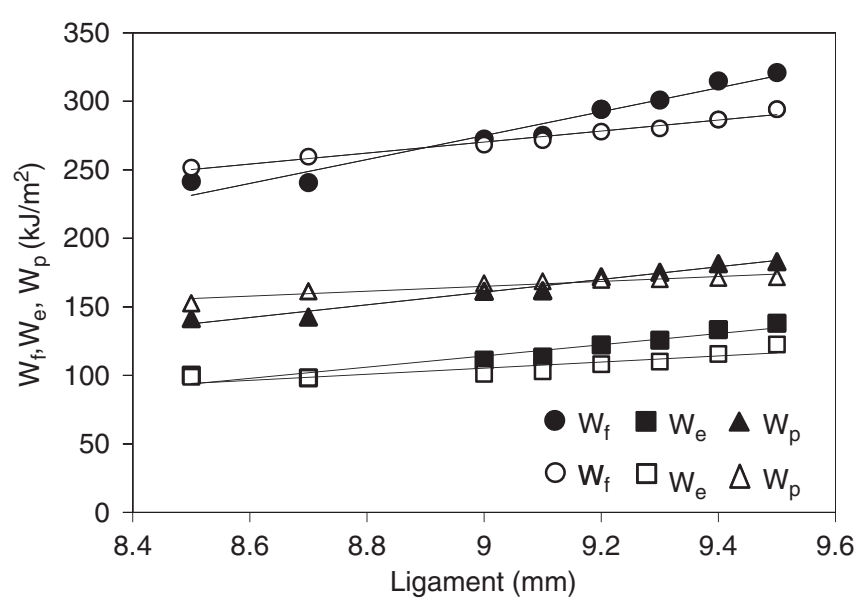

Figure 10 Total work of fracture $\left(W_{\mathrm{f}}\right)$, essential work of fracture $\left(W_{\mathrm{e}}\right)$ and nonessential work of fracture $\left(W_{p}\right)$ at different ligament depths.

equation (4). Consequently, $\left(w_{\mathrm{e}}\right)$ and $\left(\beta w_{\mathrm{p}}\right)$ are the positive intercept (at $l=0$ ) and the slope of the linear regression lines, respectively. This suggests that $\left(w_{\mathrm{e}}\right)$ is a measure of the toughness of the materials. ${ }^{11}$ Figure 10 also indicates that the slope $\left(\beta w_{\mathrm{p}}\right)$ of the materials increases with increasing ligament size, which suggests that deeper notches decreased the total work of fracture. The steeper slopes of essential $\left(W_{\mathrm{e}}\right)$ and nonessential works of fracture $\left(W_{\mathrm{p}}\right)$ contributed to a steeper total work of fracture $\left(W_{\mathrm{f}}\right)$ in VPET, which suggests a faster transition from ductile to brittle in VPET as the ligament length decreased. In contrast, a more gradual ductile to brittle transition was observed in RPET.

\section{CONCLUSIONS}

The EWF approach was used to evaluate the fracture toughness of VPET and RPET notched at shallow depths; that is, the notch root was situated within the skin region of the injection-molded dumbbell specimens. Results revealed that the skin-core structure of the materials and the location of the notch greatly influenced the fracture modes and crack-tip temperature of PET, especially in the process deformation zones. A phenomenal increase in crack-tip temperature occurred when notches were deep enough to cause stress concentration but remained within the skin region. However, there was no noticeable change in crack-tip temperature when the notch penetrated the skin into the core. The fact that full ligament yielding occurred when notches were skin deep allowed the application of EWF methods to characterize the fracture toughness of both VPET and RPET. The ductile to brittle transition was found to be more drastic in VPET compared with RPET. The more subtle ductile to brittle transition in RPET can be attributed to the more gradual crystallinity change from the skin to core regions.

1 Rittel, D. Experimental investigation of transient thermoplastic effects in dynamic fracture. Int. J. Sol. Struct. 35, 2959-2973 (1998).

2 Ogazi-Onyemaechi, B. C., Leong, Y. W. \& Hamada, H. Crack propagation behavior and toughness of V-notched polyethylene terephthalate injection moldings. J. App. Pol. Sc. 116, 132-141 (2010).

3 Nicholson, J. W. The Chemistry of Polymers 96-101 (The Royal Society of Chemistry, Cambridge, UK, 2006).

4 Godart, M. A. \& Leevers, P. Effect of skin fracture on failure of a bilayer polymer structure. Int. J. Fract. 148, 315-329 (2007). 
5 Nielsen, L. E. \& Landel, R. F. Mechanical Properties of Polymers and Composites, 2nd edn. (Marcel and Dekker, New York, 1994).

6 Takano, M. \& Nielsen, L. E. The notch sensitivity of polymeric materials. J. App. Pol. Sci. 20, 2193-2207 (1976).

7 Karger-Kocsis, J. For what kind of polymer is the toughness assessment by the essential work concept straightforward? Polymer. Bulletin. 37, 119-126 (1996).

8 Mouzakis, D. E., Papke, N., Wu, J. S. \& Karger-Kocsis, J. Fracture toughness assessment of poly(ethyleneterephthalate) blends with glycidyl methacrylate modified polyolefin elastomer using essential work of fracture method. J. App. Pol. Sci. 79, 842-852 (2001).
9 Chiou, K. C., Hsu, H. C. \& Chang, F. C. Precrack hysteresis energy in determining polycarbonate ductile-brittle transition. IV. Effect of strain rate. J. App. Pol. Sci. 65, 655-665 (1997).

10 Chen, H., Karger-Kocsis, J. \& Wu, J. Effects of molecular structure on the essential work of fracture of amorphous copolyesters at various deformation rates. Pol. 45, 6375-6382 (2004).

11 Kuno, T., Yamagishi, Y., Kawamura, T. \& Nitta, K. Deformation mechanism under essential work of fracture process in polycyclo-olefin materials. eXPRESS Pol. Letters 2, 404-412 (2008) 